\title{
Length of Barrett's oesophagus: an important factor in the development of dysplasia and adenocarcinoma
}

\author{
S Y Iftikhar, P D James, R J C Steele, J D Hardcastle, M Atkinson
}

\begin{abstract}
In a 15 year prospective study of endoscopic surveillance of columnar lined oesophagus, 102 patients with a mean follow up of $54(12 \cdot 5)$ months and total follow up of $\mathbf{4 6 2}$ years have been evaluated. Of all the sets of biopsies taken, 59 in 21 patients were found to exhibit dysplasia or carcinoma. Four male patients had carcinoma of the oesophagus, indicating a 30 times increased risk of development of adenocarcinoma in columnar lined oesophagus. The length of columnar lined oesophagus in subjects with dysplasia was significantly longer as compared with the whole group $(p=0.01)$ and when compared with the patients without dysplasia $(p=0.005)$. None of the patients with dysplasia had a columnar lined oesophagus of less than $8 \mathrm{~cm}$. Length of columnar lined oesophagus therefore seems to be a significant risk factor in the development of dysplasia and subsequent carcinoma and intensive follow up of patients with columnar lined oesophagus greater than $8 \mathrm{~cm}$ in length is recommended.

(Gut 1992; 33: 1155-1158)
\end{abstract}

Columnar lined or Barrett's oesophagus is found at endoscopy in 10 to $16 \%$ of patients with reflux oesophagitis, ${ }^{1-4}$ and the diagnosis is based on circumferential replacement of at least the lowermost $3 \mathrm{~cm}$ of the oesophagus by columnar epithelium. $^{5}$.It has been established that columnar lined oesophagus carries a risk of adenocarcinoma, ${ }^{1267}$ and the reported prevalence rate of adenocarcinoma in this condition varies between 8 and 15\%. ${ }^{12468}$ The magnitude of this risk, however, and therefore the value of endoscopic surveillance remains highly controversial..$^{89}$

In columnar lined oesophagus, the risk of malignancy is increased by approximately 350 times when compared with squamous oesophageal carcinoma in the general population. ${ }^{5}$ It is considered inappropriate, however, to compare the incidence of adenocarcinoma with that of squamous carcinoma ${ }^{5}$ and comparison of adenocarcinoma in columnar lined oesophagus with adenocarcinoma of the oesophagus without columnar lined oesophagus presents insuperable problems because it is usually impossible to be certain whether these growths have arisen in the proximal stomach or the oesophagus itself. In addition, it can be argued that nearly all true adenocarcinomas of the oesophagus arise from pre-existing columnar lined oesophagus. ${ }^{10}$ It is thus more appropriate to compare the incidence of adenocarcinoma in columnar lined oesophagus with that of adenocarcinoma of the stomach in the population at large. We have previously found that this comparison constitutes a relative risk of 61 times, ${ }^{5}$ although other studies involving regular endoscopic surveillance have reported an even higher incidence. ${ }^{811}$

It is also evident that adenocarcinoma complicating columnar lined oesophagus is often not obvious on gross endoscopic appearance and can only be diagnosed by biopsy or cytology. ${ }^{512}$ Furthermore, epithelial dysplasia, which frequently accompanies adenocarcinoma and is also regarded as its precursor, can be detected only by endoscopic biopsy. ${ }^{13}$ The significance of dysplasia in terms of clinical management is still uncertain, however, as the rate of progression to malignancy is not clear. In 1976, an endoscopic surveillance programme for columnar lined oesophagus was established at Queen's Medical Centre, Nottingham. The aim of present study was to identify any significant risk factor for the adenocarcinoma arising in Barrett's oesophagus.

\section{Methods}

\section{PATIENTS}

Between 1976 and 1990, 102 consecutive patients with a diagnosis of columnar lined oesophagus were entered into a surveillance programme involving multiple biopsies at six monthly intervals in dysplastic subjects and approximately annually in others. Those in whom a carcinoma was present at first examination were excluded from this study. All patients gave informed written consent and further consent for each endoscopy and biopsy was obtained. The diagnosis was only made if the columnar lined oesophagus extended circumferentially at least $5 \mathrm{~cm}$ from the endoscopically defined cardiooesophageal junction and histology confirmed the clinical impression.

Endoscopy was performed under benzodiazepine sedation; the presence or absence of hiaturs hernia, oesophagitis, peptic ulcer and stricture was noted. The level of the squamo-columnar
Mr S Y Iftikhar, DM, FRCS Department of Surgery, University Hospital,

Accepted for publication 20 December 1991 
TABLE I Classification of dysplasia in Barrett's oesophagus based on inflammatory bowel disease

i Negative for dysplasia

ii Indefinite for dysplasia Probably negative Unknown significance Probably positive

iii Positive for dysplasia Low grade
High grade Riddle's classification for

junction from the incisor teeth was carefully noted at each endoscopy and multiple biopsies were taken from all four quadrants at $2 \mathrm{~cm}$ intervals from the cardia upwards extending into the squamous mucosa.

Biopsy specimens were fixed in neutral buffered formalin, processed to paraffin and multiple sections from each block were stained using haemotoxylin and eosin, Alcian Blue $\mathrm{pH}$ $2 \cdot 5 /$ periodic acid Schiff and high iron diamine/ Alcian Blue $\mathrm{pH} 2 \cdot 5$. All biopsy specimens were examined by one pathologist and each was examined for histological type of epithelium present, ${ }^{14}$ the presence and type of intestinal metaplasia ${ }^{15}$ and for dysplasia or carcinoma.

A system for the grading of dysplasia in inflammatory bowel disease ${ }^{16}$ is routinely applied to columnar lined oesophagus, ${ }^{17-19}$ and the nomenclature used in this classification is shown in Table I. Dysplasia was defined as neoplastic alteration in the columnar mucosa with nuclear pleomorphism, hyperchromatism of nuclei and loss of nuclear polarity.

\section{Results}

The mean age of the 102 patients studied was 63 $(13 \cdot 5)$ years (range 18-84). The group comprised 62 men (mean age 60.3 $(12 \cdot 8)$ years (range 18-84)

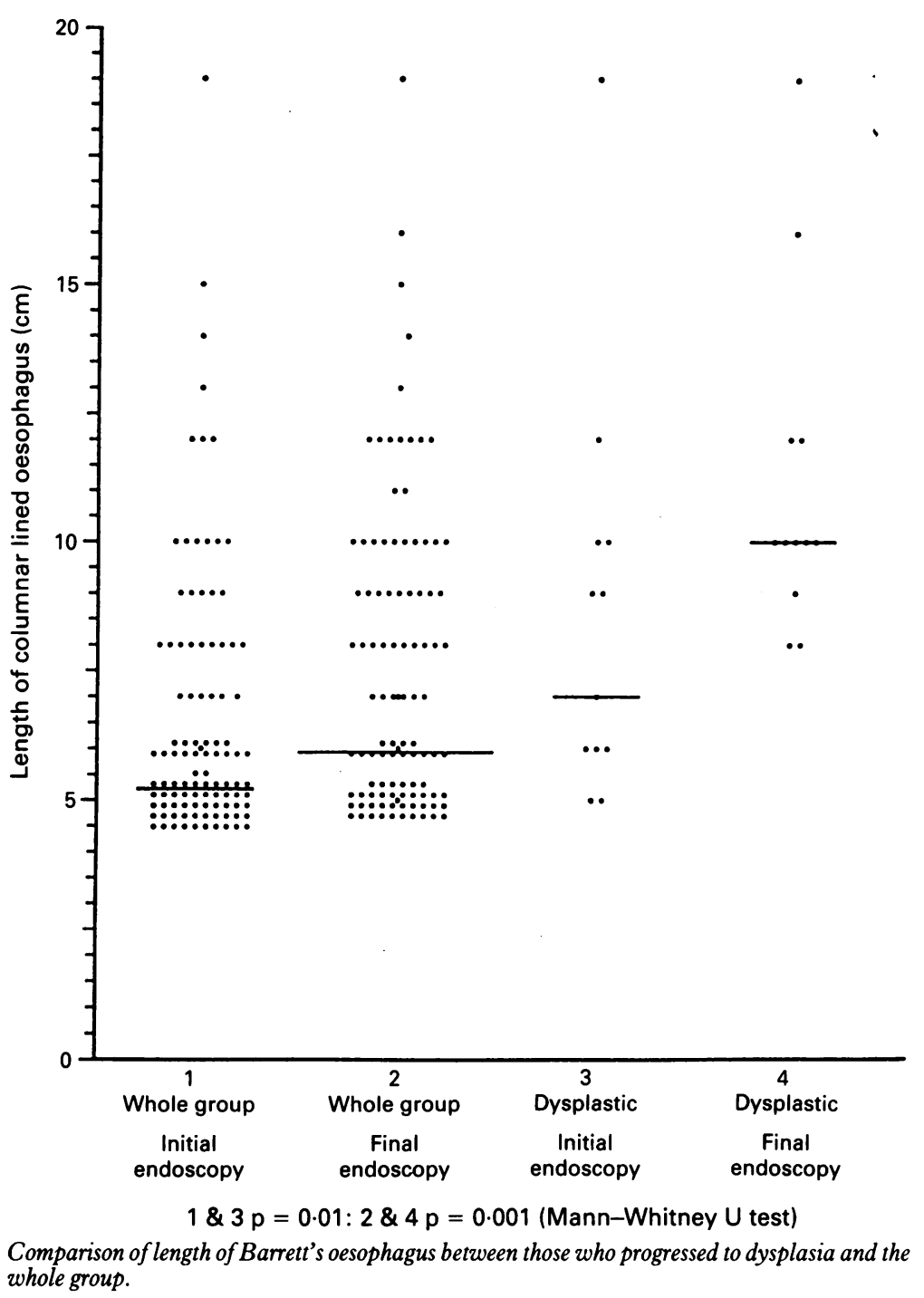

and 40 women (mean age $57 \cdot 7(11 \cdot 8)$ years (range 24-76)).

The mean follow up of the 102 patients was 54 $(12 \cdot 5)$ months with a range of 36-180 months and total follow up of 462 patient years. Five of these patients (three men and two women) died during follow up due to unrelated causes. The main presenting symptoms were heartburn (69.6\%), acid reflux (49\%) and dysphagia (44\%), and the mean duration of symptoms at initial presentation was $4.6(2.0)$ years. Endoscopy revealed oesophagitis in 62 patients $(60 \cdot 7 \%)$, hiatus hernia in $80(78.5 \%)$, Barrett's ulcer in $31(30.4 \%)$ and benign peptic stricture in 32 $(31 \cdot 4 \%)$. Despite longterm use $\mathrm{H}_{2}$ receptor blocking agents by all patients after diagnosis, progression of columnar lined oesophagus was observed in 13 patients $(12 \cdot 7 \%)$, while no regression of columnar epithelium occurred in any patient including six who had undergone anti reflux surgery.

Three hundred and seventy three sets of biopsies from 102 patients were evaluated histologically for mucosal type and dysplasia. Specialised mucosa occurring alone was found in $10 \%$, but junctional and specialised mucosa together were found in $51 \%$ of biopsies. Two hundred and forty two (65\%) biopsies contained specialised mucosa either alone or with other types of mucosa. Dysplastic changes were present in $59(15 \cdot 8 \%)$ sets of biopsies from 21 patients and negative in $314(84 \cdot 2 \%)$. The dysplasia was classified as indefinite in 14 patients and in nine of these was considered to be 'probably negative' but in five other cases it was 'probably positive'. Thus, overall, 12 patients were classed as dysplastic and of these two were found to have dysplasia at presentation. Three had high grade dysplasia and subsequently developed intramucosal carcinoma. The nine other patients with dysplasia remain well after a mean follow up of 18 months after development of dysplasia in their columnar lined oesophagus. One patient developed an invasive adenocarcinoma two years after initial endoscopy without dysplasia having been noted in previous biopsies. It is important to note that all biopsy specimens showing dysplasia contained some specialised mucosa.

The mean initial length of columnar lined oesophagus for the whole group was $6.9(2 \cdot 8) \mathrm{cm}$ as compared with $7 \cdot 6(2 \cdot 5) \mathrm{cm}$ at last endoscopy but this did not reach statistical significance. The length of columnar lined oesophagus at initial endoscopy in patients who developed dysplasia, however, was found to be significantly greater when compared with the whole group and with those who did not develop dysplasia (Figure, Table II). These differences were even greater at final endoscopy. Of the 12 patients who developed dysplasia, six had progression of their columnar lined oesophagus, compared with only seven of the 90 patients who did not; a highly significant difference $(p=0.001$ Fisher's exact test). All patients who developed dysplasia had a columnar lined oesophagus of $8 \mathrm{~cm}$ or more at the time of diagnosis and no patient with a columnar lined oesophagus of less than $8 \mathrm{~cm}$ has been found to have dysplasia. Carcinoma was identified in only one patient by gross endoscopic 
TABLE II Relationship between length of Barrett's oesophagus and dysplasia

\begin{tabular}{llcc}
\hline & \multicolumn{3}{c}{ Length of Barrett's oesophagus } \\
\cline { 2 - 4 } & Mean $(S D) \mathrm{cm}$ & Median cm & Range cm \\
\hline Whole group & & & \\
1 Initial endoscopy $(\mathrm{n}=102)$ & $6 \cdot 93(2 \cdot 79)$ & $6 \cdot 0$ & $5 \cdot 0-19 \cdot 0$ \\
2 Final endoscopy $(\mathrm{n}=102)$ & $7 \cdot 63(2 \cdot 92)$ & $7 \cdot 0$ & $5 \cdot 0-19 \cdot 0$ \\
Non-dysplastic Barrett's & & & $5 \cdot 0-15 \cdot 0$ \\
3 Initial endoscopy $(\mathrm{n}=90)$ & $6 \cdot 6(2 \cdot 4)$ & $6 \cdot 0$ & $5 \cdot 0-15 \cdot 0$ \\
4 Final endoscopy $(\mathrm{n}=90)$ & $6 \cdot 8(2 \cdot 5)$ & $6 \cdot 2$ & $5 \cdot 0-19 \cdot 0$ \\
Dysplastic Barrett's & $9 \cdot 3(3 \cdot 7)$ & $9 \cdot 0$ & $8 \cdot 0-19 \cdot 0$ \\
5 Initial endoscopy $(\mathrm{n}=12)$ & $10 \cdot 75(3 \cdot 4)$ & $10 \cdot 0$ & \\
6 Final endoscopy $(\mathrm{n}=12)$ &
\end{tabular}

Mann Whitney U-test: 1 v 2 NS; 1 v $5 p=0.01 ; 2$ v $6 p=0.001 ; 3$ v $5 p=0.005$.

appearances while in three other patients the diagnosis was only made by random biopsy.

Nine patients had surgical treatment; six had antireflux surgery and three had oesophagectomy for carcinoma. One patient died as a direct consequence of oesophagectomy, while the other two are alive and well five years post oesophagectomy. In the fourth patient with (intra mucosal) carcinoma surgery was contraindicated because of concomitant carcinoma of the prostate. This patient died six years post diagnosis as a result of carcinoma of prostate and was asymptomatic from his oesophageal carcinoma.

\section{Discussion}

It is well established that columnar lined oesophagus carries a risk of malignant change, but the degree of risk varies between reported studies. In the first 10 years of surveillance of our Nottingham group there was a relative risk of one cancer per 56 patient years, but after 15 years' follow up this has reduced to one cancer developing per 115.5 patient years. The incidence of carcinoma in columnar lined oesophagus in the present series is 866 per $10^{5}$ patients per year, and if compared with squamous carcinoma of the oesophagus the relative risk of adenocarcinoma in columnar lined oesophagus is increased by 169 times. It is more appropriate, however, to compare the incidence of adenocarcinoma in columnar lined oesophagus with that of gastric cancer which is 28.8 per $10^{5}$ patient per year $^{21}$; this comparison gives a relative risk of 30 times, which is still significantly higher.

Even though marked heterogeneity of the mucosa is found in columnar lined oesophagus, ${ }^{1+2022}$ a mixture of junctional and specialised type is more common and was found in more than $50 \%$ of our biopsies. The presence of specialised type mucosa is of some importance as all 59 dysplastic biopsy specimens contained specialised mucosa but as $65 \%$ of biopsies showed this appearance, it cannot be regarded as a useful marker for impending malignancy.

Dysplasia thus remains the only reliable biomarker for adenocarcinoma ${ }^{1323}$ and there may be a long latent period of months to years with a progression in severity of the dysplasia before the development of adenocarcinoma. ${ }^{513}$ In three of our four cases of malignancy there was progressive worsening of dysplasia, but in one carcinoma developed without previous biopsy evidence of dysplasia. The interval in this case between an apparently normal biopsy and the biopsy showing malignancy was one year and it is possible that the dysplasia-carcinoma sequence was not detected.

There are wide interobserver variations in the assessment of dysplasia ${ }^{2+}$ and the anatomical distribution of dysplasia within the oesophagus may be patchy. ${ }^{12}$ We made no attempt, however, to assess intra or inter observer variability because it has been shown that experienced pathologists can reliably distinguish high grade dysplasia from other lesions $\mathrm{s}^{25}$ and all our biopsies were reviewed by one senior pathologist. In addition, every attempt was made to overcome sampling error by a systematic multiple biopsy technique.

The length of columnar lined oesophagus has not previously been considered to be an important risk factor. Van der Veen and his colleagues ${ }^{26}$ have pointed out that in their series of surveillance of Barrett's oesophagus all four patients who developed carcinoma of the oesophagus had columnar lined oesophagus of more than $8 \mathrm{~cm}$. No account of relationship of dysplasia and the length of columnar lined oesophagus was given. In our patients, the columnar lined oesophagus was significantly longer in those who developed dysplasia as compared with the whole group, and no patient with a columnar lined oesophagus of less than $8 \mathrm{~cm}$ was found to have dysplasia or adenocarcinoma. Six of the 12 patients who had normal histology at presentation and went on to develop dysplasia had progression of their columnar lined oesophagus and it occurred within two years of endoscopic surveillance. We therefore regard patients with a columnar lined oesophagus of $8 \mathrm{~cm}$ or more to be at particular risk, and we feel that this group should be more carefully monitored, with six monthly endoscopy and biopsies taken from all four quadrants at $2 \mathrm{~cm}$ intervals from cardia upwards. Patients who have evidence of progression of columnar lined oesophagus between endoscopies should be followed in a similar manner. We would suggest that patient with a static columnar lined oesophagus of less than $8 \mathrm{~cm}$ should have endoscopy at yearly intervals. Patients with Barrett's oesophagus remain at potential risk of developing adenocarcinoma of the oesophagus and should be followed up life long, however, obvious unfitness for oesophagectomy because of age or other disease in some patients will preclude such exercise.

In the present study of 102 patients there have been no complications from sedation, endoscopy or biopsy which suggests that the benefit achieved by diagnosing early cancers as well as treating benign complications of columnar lined oesophagus out weighs the risk of endoscopy. We have not been able to determine the time lag of progression of dysplasia to carcinoma, however, and one of our patients with intramucosal carcinoma had no symptoms for six years until he died of unrelated causes. This calls into question whether the risk of oesophagectomy could ever be justified for dysplasia alone, and many more years of careful follow up will be required to fully assess the value of surveillance for Barrett's oesophagus. 
1 Naef AP, Savary M, Ozzello L. Columnar lined lower oesophagus: an acquired lesion with malignant predisposition. Report of 140 cases of Barrett's oesophagus with 12 adenocarcinomas. $\mathcal{F}$ Thorac Cardiovasc Surg 1975; 70: 826-35.

2 Sarr MG, Hamilton SR, Marrone GC, Cameron JL. Barrett's esophagus: Its prevalence and association with adenocarcinoma in patients with symptoms of gastro-esophageal reflux. Am $\mathcal{F}$ Surg 1985; 149: 187-92.

3 Cooper BT, Barbezat GO. Barrett's oesophagus: a clinical study of 52 patients. QF Med 1987; 62: 97-108.

4 Winters C, Spurling TJ, Chobanian SJ, Curtis DJ, Esposito inters C, Spurling TJ, Chobanian SJ, Curtis DJ, Esposit RL, Hacker JF, et al. Barrett's oesophagus - a prevalent occult complication of gastro-oesophageal reflux. Gastro-
enterology 1987; 92: 118-24.

5 Robertson CS, Mayberry JF, Nicholson DA, James PD Atkinson $M$. Value of endoscopic surveillance in the detection of neoplastic changes in Barrett's oesophagus. BrF Surg 1988; 75: 760-3

6 Cameron AJ, Ott BJ, Payne WS. The incidence of adenocarcinoma in a columnar lined Barrett's oesophagus. $N$ Eng $\mathcal{f}$ Med 1985; 313: 857-9.

7 Spechler SJ. Endoscopic surveillance for patients with Barrett's oesophagus: does cancer risk justify the practice? Ann Intern Med 1987; 106: 902-4.

8 Spechler SJ, Robbins AH, Rubins HA, Vincent ME, Heeren T, Doos WG, et al. Adenocarcinoma and Barrett's oesophagus: an over-rated risk. Gastroenterology 1984; 87: phagus:

9 Spechler SJ. Barrett's oesophagus: what's new and what to do. Am ₹ Gastroenterol 1989; 84: 220-3.

10 Haggit RC, Reid BJ, Rabinovitch PS, Rubin CE. Barrett's oesophagus. Correlation between mucin histochemistry flow cytometry and histologic diagnosis for predictin increased cancer risk. Am F Pathol 1988; 131: 53-61.

11 Sampliner RE, Kogan FJ, Morgan TR, Tripp M. Progression - regression of Barrett's oesophagus. Gastroenterology 1985 88: A1567.

12 Reid BJ, Haggit RC, Rubin CE, Roth G, Surawicz CM, Van Belle G, et al. Observer variation in the diagnosis of dysplasia in Barrett's oesophagus. Hum Pathol 1988; 19: 166-78.

13 Lee RG. Dysplasia in Barrett's oesophagus. A clinicopathologic study of six patients. Am J Surg Pathol 1985; 9: p45-52.
14 Paull A, Trier J, Dalton M, Camp R, Loeb P, Goyal R. The histological spectrum of Barrett's oesophagus. $N$ Einglf Med 1976; 295: 476-80.

15 Fillipe MI, Jass JR. Intestinal metaplasia subtypes and cancer risk. In: Fillipe MI, Jass JR, eds. Gastric carcinoma. Edinburgh: Churchill Livingstone, 1986.

16 Riddell RH, Goldman H, Ransohoff DF, Appleman HD, Fenoglio $\mathrm{CM}$, Haggitt RC, et al. Dysplasia in inflammatory
bowel disease. Standardised classification with provisional clinical applications. Hum Pathol 1983; 14: 931-68.

17 Skinner DB, Walther BC, Riddell RH, Schmidt H, Iascone C, Demeester TR. Barrett's oesophagus: comparison of benign and malignant cases. Ann Surg 1983; 198: 55+66.

18 Spechler SJ, Goval RK. Barrett's oesophagus. N Engl f Med 1986; 315: 362-71.

19 Hamilton SR, Smith RRL. The relationship between columnar epithelial dysplasia and invasive adenocarcinoma arising
in Barrett's oesophagus. Am f Clin Pathol 1987; 87: 301-12.

20 Rothery GA, Patterson JE, Stoddard CJ, Day DW. Histological and histochemical changes in the columnar lined (Barrett's) oesophagus. Gut 1986; 27: 1062-8.

21 Langman MJ. The epidemiology of chronic digestive discase. Chicago: Year Book Medical Publishers, 1986.

22 Thompson JJ, Zinsser KR, Enterline HT. Barrett's metaplasia and adenocarcinoma of the oesophagus and gastroplasia and adenocarcinoma of the oesophagus and
oesophageal junction. Hum Pathol 1983;14: +2-61.

23 Reid BJ, Haggit RC, Rubin CE, Rabinovitch PS. Correlation between flow cytometry and histology in detection of patients at risk for adenocarcinoma. Gastroenterology 1987 93: 1-11.

24 Reid BJ, Weinstein WM, Lewin KJ, Haggit RC, Van Deventer G, Den Besten L, et al. Endoscopic biopsy can Deventer $G$, Den Besten $L$, et al. Endoscopic biopsy can
detect high grade dysplasia or early adenocarcinoma in detect high grade dysplasia or early adenocarcinoma in Barrett's oesophagus without grossly recog
lesions. Gastroenterology 1988; 94: 81-90.

25 Reid BJ, Haggit RC, Rubin CE, Roth G, Surawicz CM, Van Belle G, et al. Criteria for dysplasia in Barrett's oesophagus: a co-operative consensus study. Gastroenterologv 1985;88: 1552.

26 Van Der Veen AH, Dees J, Blankensteijn JD, Van Blankestein $M$. Adenocarcinoma in Barrett's oesophagus: an overated risk. Gut 1989; 30: 14-8 